\title{
O uso da tecnologia no auxílio à preservação do idioma indígena: o caso Xakriabá Dener Guedes Mendonça' ${ }^{1}$, Joselice Ferreira Lima ${ }^{1}$, Claudio Alexandre Gusmão ${ }^{1}$ \\ ${ }^{1}$ Instituto Federal do Norte de Minas Gerais (IFNMG) - Campus Januária-MG, Brasil denerguedesbnb@yahoo.com.br, joselice.f.lima@gmail.com, claudioagusmao@gmail.com
}

\begin{abstract}
The article deals with the use of technology to aid the indigenous vocabulary preservation process working as a care resource in teaching learning this language. For it has an online software tool that allows the user to learn the indigenous language as the catalogs. Indigenous words before passed only verbally will be available in text format, picture and sound. It used the case of Xakriabá people in the study and contextualization of this text and system. It is concluded that the technology can be used in the Indian vocabulary storage, contributing to its preservation and also used in Indian literacy activities.
\end{abstract}

Resumo. $O$ artigo trata do uso da tecnologia no auxílio ao processo de preservação do vocabulário indígena funcionando como recurso assistencial no ensino aprendizagem deste idioma. Para isso apresenta uma ferramenta computacional on-line que permite ao usuário aprender a língua indígena à medida que a cataloga. As palavras indígenas antes repassadas apenas verbalmente estarão disponíveis em formato de texto, imagem e som. Foi utilizado o caso do povo Xakriabá no estudo e contextualização deste texto e sistema. Conclui-se que a tecnologia pode ser usada no armazenamento do vocabulário indígena, contribuindo para sua preservação e também utilização em atividades de alfabetização de índios.

\section{Introdução}

Na sociedade atual percebe-se que as Tecnologias de Informação (TI) estão cada vez mais presentes nas atividades do dia a dia. A temática em torno da disponibilidade de acesso à informação tem ganhado evidência, motivada, entre outros aspectos, pelo aumento na oferta de serviços e soluções que utilizam recursos on-line. Nas aldeias e comunidades indígenas também existe a demanda por acesso a informação e o uso de recursos da TI (computadores, smartphones, internet, etc). Nesse cenário, a Tecnologia da Informação constitui a base dessa transformação e o desenvolvimento progressivo de aplicações e tecnologias inseriu também a internet de forma definitiva no cotidiano das pessoas (Barvinski, 2012). Entende-se que esses recursos tecnológicos são alternativas viáveis de serem inseridos e utilizados também em ambientes indígenas.

A internet inclusive aparece como um dos principais fatores de uso e interesse na população indígena, como observado por Renesse (2010), que lembra a existência de pontos de internet em escolas, organizações comunitárias e associações presentes em aldeias indígenas. Muitos índios também usam laptops para acessar a internet através das antenas em repartições públicas como, por exemplo, nos pelotões do exército em fronteiras indígenas.

A tecnologia vem despertando interesse das comunidades indígenas devido aos recursos trazidos pelo ambiente web, embora ainda em estágio inicial. Muitas tribos já 
utilizam aparatos tecnológicos em seu dia a dia e se beneficiam na medida em que essas novas formas de interação auxiliam na disseminação de seus costumes e conhecimentos (Renesse, 2010).

O acesso à tecnologia da informação traz reflexões sobre a distância e o tempo, estes tendem a desaparecer com o uso dos recursos tecnológicos, mas ao invés de provocar a homogeneização das culturas, ajuda a manter identidades culturais e linguísticas, dando visibilidade a questões locais e fazendo com que os povos não queiram modos uniformizantes para sua concepção, mas sim, apresentar seu modo de vida em âmbito global.

O contato tecnológico, uma vez realizado, estabelece irreversível ordem para as sociedades indígenas. Se antes as gerações mais velhas não dominavam o português, hoje o que se observa é o fato de as crianças indígenas falarem apenas a língua portuguesa. É neste sentido que a utilização de recursos digitais pode garantir que os jovens indígenas tenham acesso à cultura ocidental, mas que também possam se fazer visíveis e presentes na sociedade mediante à disseminação de sua cultura (Costa, 2011).

A inclusão dos indivíduos nas novas tecnologias à medida que aprendem e reestruturam sua língua indígena não é simplesmente capacitá-los para que sejam capazes de interagir com as máquinas; o desafio é promover uma mudança social com foco na preservação de sua identidade cultural, em especial, no seu vocabulário. Neste contexto, o uso de recursos através do computador já está sendo difundido em função das facilidades proporcionadas por meio da internet no uso de redes sociais. Entretanto, dentro desta realidade, observa-se que a disseminação do conhecimento (língua indígena) é feita de forma oral pelos índios. Ainda são pouco utilizados os recursos de documentação, inclusive tecnológicos, como uma forma de armazenar a escrita de sua língua e difundir sua correta pronúncia. Diante desta lacuna pergunta-se: - Como organizar a escrita e o som (pronúncia) das palavras indígenas de modo a contribuir para sua preservação e repasse para as futuras gerações?

$\mathrm{O}$ artigo apresenta o resultado de um projeto de pesquisa que culminou no desenvolvimento de um Sistema para Catalogar Palavras Indígenas (SISCAPI), que busca oferecer uma alternativa tecnológica a ser empregada no auxílio à preservação do costume e cultura indígenas, através do armazenamento de suas palavras e pronúncia, neste caso, o vocabulário Xacriabá. Para isso, utiliza uma ferramenta computacional e on-line, que permite ao usuário aprender a língua indígena à medida que a cataloga. A relevância da ferramenta está em armazenar o vocabulário indígena e na possibilidade de ser utilizada em atividades de alfabetização e inclusão digital de índios.

O artigo está estruturado a partir desta Seção de introdução; a Seção 2 discute sobre a cultura indígena e a tecnologia, aborda o caso Xakriabá, a importância da educação bilíngue e mostra as iniciativas em recursos tecnológicos na preservação da cultura indígena; a Seção 3 apresenta a metodologia e o processo de desenvolvimento da ferramenta; a Seção 4 apresenta e discute os desafios e possibilidades referentes ao uso de tecnologia e, finalmente a Seção 5 faz as considerações finais e aponta os trabalhos futuros.

\section{A Cultura Indígena e a Tecnologia}

$\mathrm{Na}$ sociedade atual as organizações sociais estão sujeitas a influências de várias naturezas; em alguns casos essas mudanças são mais constantes em função do fluxo de 
pessoas, acarretando em miscigenação ou até mesmo em perda do vocabulário, tal como nas aldeias indígenas. Um dos problemas percebidos com a perda do vocabulário indígena é a carência de meios de documentação de sua escrita e pronúncia, bem como o significado relacionado com as palavras em português.

Preservar os idiomas indígenas é garantir que parte da história permaneça intacta e se perpetue como patrimônio nacional. A língua diz muito sobre seu povo. É inegável que a parte indígena da população brasileira tenha contribuído para a língua portuguesa atual.

No âmbito de um estado moderno uma das maiores ameaças à sobrevivência das línguas de minorias étnicas é a ausência de informações sobre sua existência. Não havendo notícias da presença de uma dada língua no estado, nenhuma medida administrativa será tomada com respeito a sua preservação ou promoção e nenhum projeto de ação urgente será apoiado (Rodrigues, 2005, p. 01).

"Vivem hoje no Brasil duzentos e quinze povos indígenas. Esses povos se diferenciam de muitas maneiras. Geralmente são classificados segundo a sua filiação linguística" (MEC, Documento Base Indígena, 2007, p. 29). A língua indígena sendo um fator determinante em sua constituição agrega não só o núcleo classificatório de um povo, mas toda a sua característica presente no uso da língua.

[...] cabe ao estado brasileiro reconhecer o valor de sua especificidade linguística e cultural, não só declarando-as patrimônio imaterial da nação, mas apoiando as pesquisas e ações educacionais apropriadas para documentá-las e analisá-las cientificamente e fomentando programas educacionais específicos, que, com professorado indígena bilíngue, assegurem a aprendizagem de novos conceitos, hoje necessários, sem perda das línguas nativas e dos valores culturais que elas traduzem (Rodrigues, 2005, p. 05).

É necessário considerar que cada povo tem sua língua, sendo sua preservação altamente necessária, independentemente do grau de parentesco entre elas, pois se a língua está atrelada à cultura de cada povo, catalogá-las é permitir que cada dialeto continue existindo e que a bagagem cultural de um povo permaneça intacta. Existem inúmeras aldeias, cada uma com sua língua e costume. O povo Xakriabá, oriundo do Norte de Minas Gerais, por exemplo, possui ramificações diversas; seu vocabulário, além de ser usado para a comunicação, é também determinante em sua classificação.

Os Xakriabás são identificados como Jê, subdivisão Akwê. Vivem hoje, após intensa luta pela posse da terra contra posseiros e fazendeiros da região, na denominada Reserva Indígena Xakriabá, demarcada e homologada, localizada no município de São João das Missões-MG (Escobar, 2011, p. 02).

Olson (1997) faz uma observação interessante sobre o significado da oralidade e da escrita para os Xakriabás, quando diz que os mesmos "propõem a interdependência entre o oral e o escrito. Uma das crenças discutidas por Olson é a de que a fala é propriedade do povo, solta e desregrada, e a escrita instrumento de precisão e poder" (apud Escobar, 2012, p. 189).

Ressalta-se a importância de se preservar a língua Xakriabá e manter um registro e disseminação desta cultura linguística, pois se a fala é um fator determinante 
de interação na comunidade indígena e a escrita algo utilizado para registrar as ações no ambiente contemporâneo, permitir que a língua indígena sobreviva e esteja registrada impede que ela se perca com o tempo e dá sustentabilidade documental à história dessa comunidade.

Quanto ao uso de tecnologia, Kirner (2013) levanta questões que devem ser observadas no desenvolvimento de aplicações voltadas ao armazenamento e disseminação do conhecimento como a utilização de elementos populares que envolvam "seu uso em todas as camadas sociais, o uso de equipamentos simples e baratos ou gratuitos, o uso de software livre, o acesso intuitivo sem exigência de destreza, a capacidade de adaptação, [...] etc" (apud Seabra, 2014, p. 1180).

$\mathrm{Na}$ visão de Seabra (2014), a oportunidade de disponibilizar e explorar ferramentas que promovam o incentivo e a motivação dos usuários caracteriza uma postura responsável e representa uma mudança necessária aos processos educacionais.

Corroborando com o uso da Tecnologia da Informação, Selleri (2013) destaca que a internet é sempre lembrada pelos indígenas como recursos necessários para promover a inclusão digital nas suas comunidades, seguida por laboratórios de informática e oferta de cursos. Entende-se que a elaboração de propostas que atendam as demandas relacionadas à infraestrutura e treinamento, além de um estudo mais aprofundado acerca dos impactos que a TI acarreta deve ser pensado.

\subsection{Possibilidades da Educação Bilíngue}

É possível utilizar a própria língua indígena para alfabetização (ler e escrever) de índios, facilitando assim o aprendizado do português, ou vice-versa; assim, o conhecimento se torna mais significativo e dentro da verdadeira proposta da educação bilíngue indígena.

A educação indígena acabou tendo como referência o sistema formal, baseada no letramento e na escola. Consideramos, então, que tudo o que se formulou e executou até agora é muito mais "educação escolar indígena" do que "educação indígena" propriamente dita, entendida esta última como sendo os processos de socialização e disseminação de conhecimentos próprios e internos de cada cultura indígena (EM ABERTO, 1994).

A própria comunidade indígena deseja aprimorar e transmitir seus ensinamentos; por isso surgem cada vez mais escolas indígenas, mas é preciso que elas tenham a capacidade de ensinar mediante a expectativa apresentada pela aldeia. Os índios desejam dominar a escrita de uma língua, seja sua própria, o português ou mesmo as duas conjuntamente.

[...] o binômio oral/escrito vem sendo concebido e realizado, na escola e mesmo fora dela, distintivamente em duas línguas: o lugar do oral, no meu entender, está sendo ocupado preferencialmente pelas línguas indígenas, quando língua materna ou $1^{\mathrm{a}}$ língua. O lugar da escrita pela língua portuguesa, na maioria dos casos, $2^{\mathrm{a}}$ língua destes falantes (EM ABERTO, Entre o Silêncio em Língua Portuguesa e a Página Branca da Escrita Indígena, 1994, p. 55).

Existe uma necessidade latente de permitir que a língua indígena também seja grafada e possa ser utilizada conjuntamente com o português, mas a grafia indígena não pode ser algo automático; deve representar a importância que possui no dia a dia oral das comunidades indígenas. É importante que ao aprender a grafar uma nova palavra 
indígena, uma imagem ou um som representativo seja a ela atrelado. Assim, o desenho figurativo do conhecimento adquirido "vem apoiando e reforçando essa tendência de métodos difundidos de alfabetização indígena, baseado na proposta freiriana de aquisição linguística a partir de um universo de itens lexicais relativos ao cotidiano, culturalmente relevantes [...]" (EM ABERTO, Educação Indígena no Brasil: conquistas e desafios, 1994, p. 62 e 63).

O aprendizado significativo e bilíngue discutido aqui vale para ambas as línguas (indígena e portuguesa). É no desenvolvimento dessas capacidades cognitivas voltadas à formação ou aprimoramento da competência pessoal em que o uso da computação se faz necessária (Barvinski, 2012). O uso da tecnologia e sistemas pode ser uma maneira de documentar o vocabulário indígena ainda presente em algumas regiões do Brasil, garantindo que esse material sirva de apoio à preservação da língua nativa e funcione como auxílio em atividades de alfabetização indígena.

\subsection{Recursos Tecnológicos na Preservação da Cultura Indígena}

O Google lançou em 2012 um projeto para preservar e garantir a sobrevivência de dialetos indígenas no mundo; trata-se do "Idiomas em risco",", um site que reúne um catálogo de culturas espalhadas pelo mundo (Kleina, 2012). A plataforma é colaborativa e depende de que as pessoas apresentem as informações. Apesar dessa iniciativa, as informações presentes no site são poucas e a colaboração tímida. Tal fato pode ser explicado pela plataforma de interação ser confusa, muito tecnológica e pesada para os recursos tecnológicos utilizados pela grande maioria das pessoas.

No Brasil, aparelhos celulares estão sendo usados na Amazônia para ajudar a coletar histórias da literatura oral indígena. O aplicativo chamado Aikuma não utiliza a escrita e funciona com ícones; após gravar as histórias antigas e tradicionais através de smartphones, o sistema compartilha o conteúdo com os outros telefones da rede. Com o áudio disponível em todos os celulares, ele poderá ser adaptado para o português por qualquer pessoa conectada à rede. A tradução é feita frase por frase e no final do processo, um CD será gravado com a história e a tradução (Neher, 2013). O aplicativo se preocupa com o áudio, mas não possui a possibilidade de armazenamento escrito da palavra; além disso, o produto final é um $\mathrm{CD}$, dificultando as possibilidades de inserção de novas informações. É necessário lembrar a importância do registro escrito do vocabulário de tais comunidades, que representa um material importante para o estudo da língua e preservação para repasse e aprendizado.

Ferramentas personalizadas para atender as reais necessidades de aprendizagem são necessárias; não basta inserir o indivíduo em um ambiente informatizado, pois "os conteúdos, mesmo que mais enriquecidos do que os da sala de aula tradicional, continuam sendo de uso geral" (Gomes, 2012, p. 150). O conceito discutido neste tópico faz abordagem às "ferramentas para criação de conteúdos". "A W3C (World Wide Web Consortium $^{2}$ ) define ferramenta de autoria como qualquer software, ou coleção de componentes de software, que os autores podem usar para criar ou modificar o conteúdo e disponibilizá-lo para uso por outras pessoas" (apud Rodrigues, 2014, p. 1004).

Apesar do pensamento popular de que os novos aparatos tecnológicos acabam com a cultura tradicional, usar a tecnologia como meio de preservação dos dialetos

\footnotetext{
${ }^{1}$ Projeto Idiomas em Risco - http://www.endangeredlanguages.com/

${ }^{2}$ W3C - http://www.w3.org/standards/agents/authoring
} 
indígenas é uma forma inteligente de permitir que ambas coexistam mutuamente e que ao invés de se excluírem, trabalhem conjuntamente para a preservação da língua indígena.

O uso de recursos tecnológicos para trabalhar novos modos de disponibilizar a informação e o conhecimento torna-se uma alternativa promissora na educação indígena. A partir da visão do uso da tecnologia como meio de auxiliar a preservação da cultura linguística indígena é que foi direcionado o desenvolvimento do sistema.

\section{Metodologia}

A metodologia adotada utilizou-se de pesquisa bibliográfica e documental que buscou subsídios para fundamentar o desenvolvimento da pesquisa e da ferramenta. Quanto ao método de pesquisa é exploratória descritiva, de forma a atribuir e analisar as características linguísticas pertencentes ao povo Xakriabá. Os dados foram obtidos através de visita à Terra Indígena Xakriabá.

Quanto à programação, foram utilizadas ferramentas open source e multiplataforma; optou-se pelo desenvolvimento web que permite maior armazenamento e acesso aos dados presentes no SISCAPI.

\subsection{Desenvolvimento do SISCAPI}

O desenvolvimento seguiu uma estrutura orientada a objeto e específica para o cadastro e armazenamento de palavras (texto), imagens e sons, visando a ofertar os serviços de busca e aprendizado das línguas cadastradas. Os arquivos de imagem e som possuem um limite de tamanho do arquivo de $2 \mathrm{MB}$, tendo em vista que esse valor atende à necessidade audiovisual requisitada. $\mathrm{Na}$ modelagem caracterizaram-se as informações que seriam cadastradas no sistema, tais como a palavra em indígena e seu sinônimo em português; também existe a língua, o povo, observações e os usuários.

O intuito é permitir a integração dos povos indígenas existentes através de seus vocabulários, utilizando-se deste sistema que será de domínio público com o propósito de preservar as línguas faladas nas tribos espalhadas pelo Brasil, funcionando também como apoio ao processo de ensino aprendizagem do idioma indígena. O SISCAPI permite a participação colaborativa dos usuários, que cadastram os dados relativos à constituição das informações; isto dá autonomia para que os próprios participantes se autorregulem. Para a segurança, foi implementado um $\log$ de $\operatorname{Dados}^{3}$, uma forma de gravar os eventos realizados pelos participantes dentro do sistema e identificar possíveis erros. Na existência de várias comunidades ou línguas indígenas é possível a vinculação de ambas no SISCAPI, o que permite a comparação e integração entre as tribos, referente ao vocabulário, oferecendo assim uma maneira uniforme e centralizada de acesso.

\subsection{Visão do Sistema}

O SISCAPI cataloga palavras do vocabulário indígena através do armazenamento das palavras (escrita), seu som (pronúncia) e sua imagem (identidade visual). Na página inicial são apresentadas informações gerais sobre o sistema, sua função, manual do usuário, como gravar pronúncia e imagem, contato e outras informações (Figura 1).

\footnotetext{
${ }^{3}$ Log de Dados: http://www.tiagomatos.com/blog/voce-sabe-o-que-e-log
} 


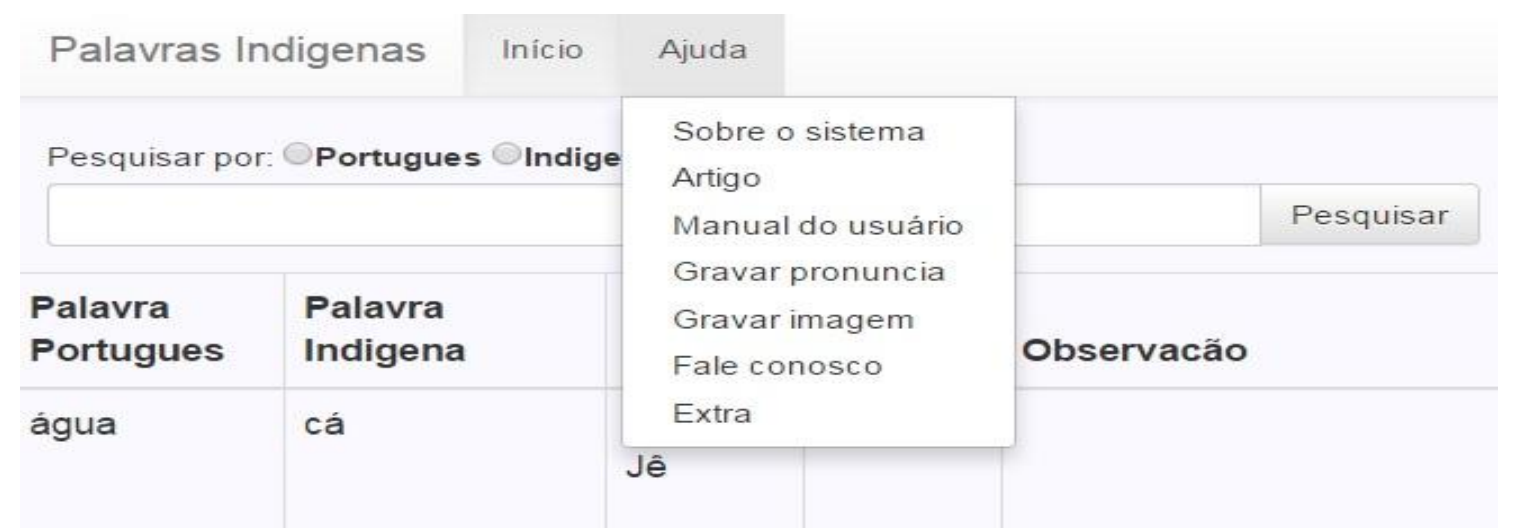

Figura 1. Tela de informações do sistema - Menu Ajuda; Fonte: SISCAPI (2015).

Para incluir novas informações é necessário ser cadastrado no sistema. A participação é feita mediante solicitação e posterior aprovação por membros já cadastrados. Dentro deste contexto fica claro que o trabalho de participação no SISCAPI visa a contribuir para que apenas usuários diretamente ligados à temática indígena linguística possam interagir. Nesta etapa, ao acessar o sistema o usuário possui acesso a recursos restritos que dependem exclusivamente de seu perfil de acesso. Toda a comunicação e interação com o usuário acontecem através do navegador web onde são oferecidas as interfaces e fornecidadas e requisitadas as informações para uso.

A Figura 2 apresenta a Tela Inicial do SISCAPI, com sua ideia central, que é armazenar e disponibilizar as palavras indígenas que venham a ser cadastradas.

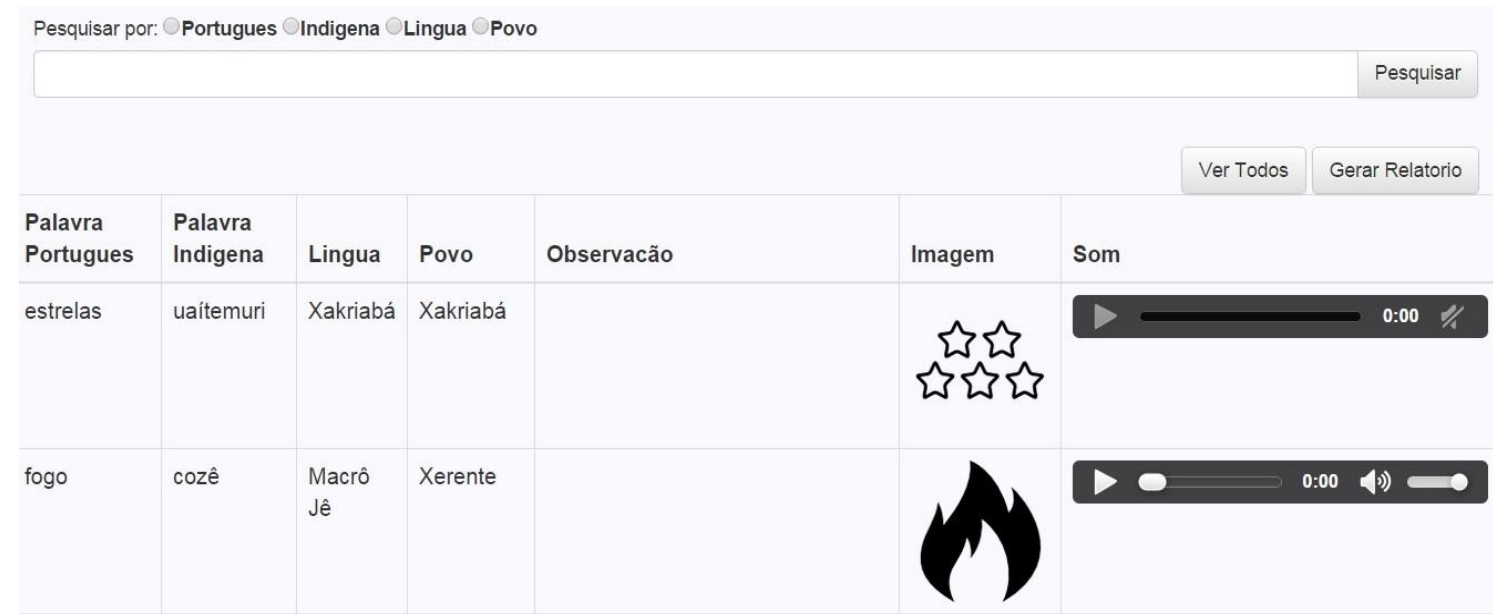

Figura 2. Palavras indígenas cadastradas; Fonte: SISCAPI (2015).

A finalidade do sistema é ser direcionado ao público indígena, relacionando-se com as propostas de resgate e preservação da língua indígena; também é esperado que novos integrantes e interessados façam parte do projeto e ajudem em seu fortalecimento.

As telas são intuitivas e oferecem um ambiente de aprendizagem ao usuário. É possível gerar um documento PDF (Figura 3) com as palavras cadastradas, permitindo o estudo off-line, análise/comparação detalhada, além de um material escrito sempre à disposição, uma espécie de minidicionário, funcionando como registro documental para a preservação escrita das palavras e o uso em atividades diversas de alfabetização de índios. 


\section{Palavras Indígenas}

Relatório com todas as palavras indígenas cadastradas no sistema

\begin{tabular}{l|l|l|l|l|}
\multicolumn{5}{c}{ Para saber mais acesse: www.palavrasindigenas.com.br } \\
\multicolumn{1}{c|}{$\begin{array}{l}\text { Palavra } \\
\text { Portugues }\end{array}$} & \multicolumn{1}{c}{ Palavra Indígena } & Lingua & Observação \\
\hline água & cá & Macrô Jê & Xerente & \\
\hline \hline anta & cutó & Xakriabá & Xakriabá & (O o bastante gutural) \\
\hline \hline árvore & odé & Xakriabá & Xakriabá & \\
\hline boca & daídaua & Xakriabá & Xakriabá & \\
\hline boca & dácedaná & Macrô Jê & Xerente & \\
\hline
\end{tabular}

Figura 3. PDF das palavras indígenas cadastradas; Fonte: SISCAPI (2015).

No SISCAPI os dados foram estruturados de acordo com os padrões de troca de informações na web e foram produzidos e armazenados de maneira que possam ser consultados e reutilizados. Este sistema foi construído, baseado na experiência línguistica indígena, tendo como base o cenário da comunidade Xakriabá. Diante disso optou-se pela utilização via web e interface intuitiva para atender à demanda observada na comunidade.

$\mathrm{Na}$ verificação do sistema realizaram-se testes com especialistas da área de desenvolvimento de sistemas, juntamente com membros da comunidade Xakriabá, previamente selecionados, quando foi possível verificar sua aplicação em atividades de auxílio a alfabetização indígena, resgate e armazenamento de sua língua nativa.

$\mathrm{Na}$ avaliação pelos membros da comunidade, percebeu-se a importância que a TI tem para as comunidades indígenas, como romper distâncias, facilitar a comunicação, valorizar e registrar a cultura, divulgar os costumes, entre outros.

O SISCAPI, em sua primeira versão, já está disponível na web para todos os interessados no assunto. No endereço eletrônico www.palavrasindigenas.com.br é possível conhecer mais sobre suas funções e solicitar a participação; aconselha-se o uso do navegador Google Chrome ${ }^{4}$.

\section{Desafios e Possibilidades}

O desafio da informática na educação indígena é a construção de ferramentas baseadas em métodos e técnicas de ensino fortalecedoras das relações humanas e agregadoras de suas diferentes culturas (costumes, línguas, etc). As tecnologias existentes devem servir para dar visibilidade e para guardar a memória das comunidades indígenas, dentro de recursos tecnológicos que atraem os índios, de forma a incluí-los.

Compreende-se que inserir o índio no uso das novas tecnologias sem perder sua identidade e cultura é um grande desafio para a área de informática. Por isso, o desenvolvimento e a disponibilização de ferramentas que atendam a essas necessidades é alternativa viável para as aldeias indígenas.

O SISCAPI surge como uma proposta de sistema on-line para auxílio no resgate e armazenamento dos dialetos indígenas contribuindo no processo de ensino

\footnotetext{
${ }^{4}$ Google Chrome: http://www.google.com.br/chrome/browser/desktop/index.html
} 
aprendizagem desse idioma através da catalogação das palavras, sons e imagens utilizadas nessas comunidades.

\section{Considerações Finais}

Relacionando a proposta do MEC (Documento Base Indígena, 2007, p. 13), que aborda que o indígena no decorrer de sua vida aprende fazendo, fica evidente que proporcionar um ambiente interativo, inclusivo e de manuseio do próprio estudante insere uma nova concepção de educação, que é "a ampliação de seu horizonte em direção à construção da autonomia a fim de que compreendam, interajam e mesmo modifiquem o seu próprio processo de formação".

Neste contexto, considerando-se que um dos principais problemas que se perpetua ao longo dos anos é a carência de registros das práticas, culturas e línguas dos povos, entende-se que a tecnologia pode contribuir significativamente para a perpetuação de sua memória. Os recursos tecnológicos são alternativas viáveis de serem demonstrados e aplicados para minimizar o problema apresentado nesta pesquisa, que é a carência de registros do vocabulário indígena.

O SISCAPI é uma solução que cataloga palavras do vocabulário indígena através do armazenamento das palavras (escrita), seu som (pronúncia) e sua imagem (identidade visual). Possibilita assim a coleta de dados, armazenamento, busca e seleção do vocabulário da tribo. Sua função é servir como instrumento de organização e recuperação de informações relacionadas ao vocabulário indígena e às práticas ligadas a sua preservação, que podem servir para diferentes propósitos, entre eles: preservação da escrita e pronuncia juntamente com a imagem de referencia, auxiliar no processo de ensino aprendizagem de idiomas indígenas, apoiar atividades de alfabetização em tribos, funcionar como recurso de compartilhamento de informações dessas comunidades, etc.

Enfim, percebe-se que existem outros sistemas voltados ao resgate linguístico indígena, mas a solução proposta apresenta uma nova opção à realidade das aldeias brasileiras, pois buscou-se suprir as falhas identificadas e analisadas nos outros produtos encontrados. O sistema pode ser considerado como um passo preliminar para o desenvolvimento de outros sistemas e o uso da tecnologia para preservação do vocabulário indígena.

\subsection{Trabalhos Futuros}

Como trabalhos futuros busca-se criar módulos no sistema para agregar novas funcionalidades, tais como: uso de caracteres especiais para grafia mais adequada da língua indígena; bate papo ou mural de recados para os participantes; tradução simultânea da palavra ou mesmo texto; outros conteúdos (matemática, música, etc).

\section{Referências Bibliográficas}

Barvinski, Carla A.; Odakura, Valguima V. V. (2012). "Desafios educacionais para o Século XXI e o papel da Informática na Educação". In Anais do Workshop de Desafios da Computação Aplicada à Educação (DesafiE).

Costa, Alda Cristina. (2011). “A comunidade indígena e o mundo tecnológico: reflexões sobre os impactos das mídias sociais na vida dos Aikewára”. In anais do $3^{\circ}$ Simpósio Hipertexto e Tecnologias na Educação. Universidade Federal de Pernambuco. 
Em Aberto. Ano XIV - no 63. (jul./set. 1994). "Tema: Educação Escolar Indígena. Instituto Nacional de Estudos e Pesquisas Educacionais (INEP)". Órgão de Divulgação do Ministério da Educação e do Desporto - Brasília.

Escobar, Suzana Alves. (2012). "Os projetos sociais do povo indígena Xakriabá e a participação dos sujeitos: entre o "desenho da mente", a "tinta no papel" e a "mão na massa". Pós-Graduação em Educação: Conhecimento e Inclusão social." Universidade Federal de Minas Gerais - Faculdade de Educação. Belo HorizonteMG.

. (2011). "Letramento Xakriabá - As Vozes, a Escrita e o Poder”. Salvador-BA. In XI Congresso Luso Afro Brasileiro de Ciências Sociais. Universidade Federal da Bahia (UFBA). Salvador-BA.

Gomes, Eduardo Henrique; et al. (2012). "Ferramentas de Autoria de Conteúdos e as Limitações para a Personalização da Educação". In Anais do Workshop de Desafios da Computação Aplicada à Educação (DesafiE).

Kleina, Nilton. (2012). "Google lança projeto para preservar idiomas em extinção". Disponível em http://www.tecmundo.com.br/google/25478-google-lanca-projetopara-preservar-idiomas-em-extincao-video-.htm. Acesso em fev/15.

MEC, Ministério da Educação; Documento Base Indígena. (2007). "PROEJA Programa Nacional de Integração da Educação Profissional com a Educação Básica na Modalidade de Educação de Jovens e Adultos. Educação profissional e tecnológica integrada á educação escolar indígena". Brasília-DF.

Neher, Clarissa. (2013). "Projeto usa smartphone para preservar línguas indígenas". Disponível em http://dw.de/p/18F8h. Acesso em fev/15.

Renesse, Nicodème. (2010). "O que pensam os índios sobre a presença da internet em suas comunidades?”. São Paulo-SP. Disponível em http://migre.me/mNHsU. Acesso em fev/15.

Rodrigues, Agnaldo Martins. (2014). "SAAPIENS: Uma Ferramenta de Autoria de Objetos de Aprendizagem e Apoio Pedagógico na Dedução Natural na Lógica Proposicional". In Anais do XXV Simpósio Brasileiro de Informática na Educação (SBIE).

Rodrigues, Aryon Dall’Igna. (2005). "Línguas indígenas brasileiras ameaçadas de extinção". São Paulo-SP. Disponível em http://migre.me/mNHcR. Acesso em fev/15.

Seabra, Rodrigo Duarte; Romano, Valter Pereira; Oliveira, Nathan. (2014). "Uma abordagem no Ensino de Variação Linguística em uma Aplicação Educacional Aberta baseada em Hipermídia”. In Anais do XXV Simpósio Brasileiro de Informática na Educação (SBIE).

Selleri, Fernando; et al. (2013). "Inclusão Digital em Escolas e Comunidades Indígenas”. In Anais do XIX Workshop de Informática na Escola (WIE). 